\title{
A Comparative Study of an Lpg- Spark Ignition Engine using Liquid Sequential Injection Technique
}

\author{
Mohd Mustaqim Tukiman ${ }^{1,{ }^{*}}$, Norrizal Mustaffa ${ }^{1}$, Mas Fawzi ${ }^{1}$, Shahrul Azmir Osman ${ }^{1}$, and \\ Rais Hanizam Madon ${ }^{1}$ \\ ${ }^{1}$ Automotive Research Group (ARG), Center for Energy and Industrial Environment Studies (CEIES), \\ Faculty of Mechanical and Manufacturing Engineering, Universiti Tun Hussein Onn Malaysia, 86400 \\ Parit Raja, Batu Pahat, Johor, Malaysia
}

\begin{abstract}
The development of liquid phase Liquefied Petroleum Gas (LPG) as an alternative fuel for the gasoline fuel is becoming popular in spark ignition engines. In this research, an experimental work was conducted on a1.6L 4-cylinder multi-port injection engine. The engine was retrofittedwith a Liquid Sequential Injection (LSI) LPG system. Its performance in terms of brake power,brake torque, brake specific fuel consumption (BSFC) and exhaust gas emissions $\left(\mathrm{CO}, \mathrm{CO}_{2}, \mathrm{HC}, \mathrm{O}_{2}\right.$, and NOx) were evaluated from $1500 \mathrm{rpm}$ to $4000 \mathrm{rpm}$ with half-open and wideopen throttle positions. In comparison with gasoline, the brake torque and brake powerfor LPG were higher, but the BSFC and exhaust emission of $\mathrm{CO}$ and $\mathrm{CO}_{2}$ for $\mathrm{LPG}$ are lower.
\end{abstract}

\section{Introduction}

Liquefied petroleum gas (LPG) is a clean alternative fuel for vehicle compared to the conventional fuels such as gasoline and diesel. In general, conventional fuels has high carbon ratio, low octane number and may gives higher emission levels compared to LPG $[1,2]$. In year 2000, more than 6 million vehicles worldwide used LPG [3]. It showed that the technologies in LPG vehicles are getting good acceptance from automotive industries and the consumers. LPG has two phases; gas and liquid. From previous studies, LPG development is divided into five generations, which the 1st-4th generation used gas phase for the fuel delivery system while the latest system uses liquid phase.

According to the Material Safety Data Sheet (MSDS) of LPG in Malaysia, it contains $60 \%$ butane and $40 \%$ propane. Generally, the composition of LPG varies followed by season, country and characteristics of the supply crude oil, the refining process and the cost refined product. Therefore there is no constant standard value for the LPG composition[4].Table 1 shows the composition of LPG as an alternative fuel of few countries.LPG is suitable as an alternative fuel for internal combustion engine (ICE). This is due to the higher Research Octane Number (RON) of LPG as compared with gasoline as

* Corresponding author: mohdmustaqimakim@gmail.com 
shown in Table 2.The liquid LPG produced lower carbon emission due to the lower carbon content in LPG as compared to the gasoline fuel[5,6]. The liquid LPG injection promised to give high resistance knocking phenomena and then the system can use a higher engine compression ratio thus the efficiencies of engine was increased [3].

The liquid phase is more effective than gas phase because a large amount of heat was absorbed into the intake air manifold due energy required to change the phase. This liquid phase is vaporized quickly, but at the same time it works as the cooler on of the mixture inside the intake manifold. As consequences, the engine received a greater mass of fuel-air mixture because greater density of cooler air and resulting volumetric efficiency and torque output were increased [4].The purpose of this study is to evaluate the performance and emission of gasoline and liquid LPG as fuel of a 4-cylinder 1.6L displacement engine using multi-point port injection (MPI).

Table 1. Composition of LPG by country [7].

\begin{tabular}{|c|c|}
\hline Country & $\begin{array}{c}\text { Propane-butane (\%) } \\
\text { by volume }\end{array}$ \\
\hline Belgium & $50-50$ \\
\hline France & $35-65$ \\
\hline Italy & $25-75$ \\
\hline Spain & $30-70$ \\
\hline United Kingdom & $100-0$ \\
\hline Germany & $90-10$ \\
\hline Malaysia & $40-60$ \\
\hline
\end{tabular}

Table 2. Selected specifications of LPG and gasoline [8].

\begin{tabular}{|c|c|c|}
\hline Property & LPG & Gasoline \\
\hline RON & $106-111$ & $92-95$ \\
\hline Specific Gravity & 0.51 & 0.74 \\
\hline $\begin{array}{c}\text { Stoichiometric A/F } \\
\text { Ratio }\end{array}$ & $15.7: 1$ & $14.7: 1$ \\
\hline $\begin{array}{c}\text { Relative } \mathrm{CO}_{2} \text { per } \\
\text { kJ }\end{array}$ & 0.885 & 1.0 \\
\hline
\end{tabular}

\section{Experimental setup}

All experiments were conducted on a Proton Gen 2 (S4PH)1.6L vehicle. Table 3 shows the specification of the test vehicle engine. The fuel delivery type of this engine is a multipoint port injection (MPI) and a prototype liquid LPG injection were used. The LPG injectors were mounted on the intake manifold that close to the inlet valve. The fuel 
pressure was regulatedin the range of 9 to 10 bar to ensure that the LPG is in the liquid phase during injection process. The system was calibrated before running the experiments to ensure the quantity of injection LPG are adequate. The injection timing for LPG was emulated from the stock electronic control unit (ECU) and this system was controlled by the additional LPG ECU system.

The emissions of carbon dioxide $\left(\mathrm{CO}_{2}\right)$, carbon monoxide $(\mathrm{CO})$, hydrocarbon $(\mathrm{HC})$, oxygen $\left(\mathrm{O}_{2}\right)$ and oxides of nitrogen $\left(\mathrm{NO}_{\mathrm{X}}\right)$ emission were measured using Autocheck gas analyzer. At the same time the data ofthe air fuel ratiowere also recorded. Next, the test vehicle was coupled to a Dynapack chassis dynamometer in order to measure the engine performance. The Bosch scan tool V1.2 management system was connected to the test vehicle during testing to enablereal time data to be recorded and monitored for each test condition. The fuel consumption was measured using Ono Sokki: FZ-2100 mass flow meter for both fuels used. A Schematic diagram of the experiment is shown in Fig. 1.The experiments were carried out at two different throttle valve positions; with half open throttle (HOT) valve position and wide open throttle (WOT) valve position. The engine speed for both throttle valve positions were tested from $1500 \mathrm{rpm}$ until 4000 rpm with $500 \mathrm{rpm}$ increment. The LPG used composes of $40 \%$ propane and $60 \%$ butane which were produced by Petroliam Nasional Berhad (PETRONAS).

\section{Result and Discussion}

Fig. 2 shows the performance of both tested fuels at two different throttle valve positions, HOT and WOT valve position. The brake torque, brake power and brake specific fuel consumption were plotted against the engine speed.The brake power of LPG and gasoline were found increase for both HOT valve position and WOT valve position. LPG produced higher brake power at WOT valve position as compared to the gasoline, meanwhile at HOT valve position brake power produced by both of fuels showed nearly similar figure except at 4000rpm where the brake power value of gasoline dropped. This is due to the fact that the LPG in liquid phase has a higher thermal efficiency than gasoline. Futhermore the temperature mixture was decreased and therefore the density and volumetric efficiency was inversely proportional condition to give positive effect [9].

The brake torque produced by LPG was compared with the gasoline fuel for both throttle valve position. The value of brake torque LPG was increase compared to the gasoline fuel.This is because the LPG cooled surrounding intake air inside intake manifold and results on the greater density [10].BSFC variation of the tested fuels is shown in Fig. 2. For both throttle valve position, BSFC of gasoline was decreased with the increased of engine speed. Meanwhile, for the LPG, the BSFC was almost consistent throughout the engine speed. The BSFC of LPG was lower than gasoline except at 3500rpm and 4000rpm engine speed for tested throttle valve position. This is because the liquid LPG has higher pressure in fuel lines, hence the higher pressure fuel of LPG was released in the cylinder and resulted on lower fuel consumption of LPG itself as compared to gasoline fuel $[8,12]$. 
Table 3. Specification of the test vehicle.

\begin{tabular}{|c|c|}
\hline Type model & Proton Gen2 (S4PH) \\
\hline Total displacement & $1.6 \mathrm{~L}$ \\
\hline Number of cylinders & 4 \\
\hline Orientation & East - West \\
\hline Valve train & DOHC 16 V \\
\hline Compression ratio & $10.0: 1$ \\
\hline Bore x stroke & $76 \mathrm{mmx} 88 \mathrm{~mm}$ \\
\hline Power & $82 \mathrm{KW} @ 6000 \mathrm{RPM}$ \\
\hline Torque & 109lb-ft@ 4000 RPM \\
\hline Fuel/ system & $\begin{array}{r}\text { Gasoline/ multipoint } \\
\text { injection }\end{array}$ \\
\hline
\end{tabular}

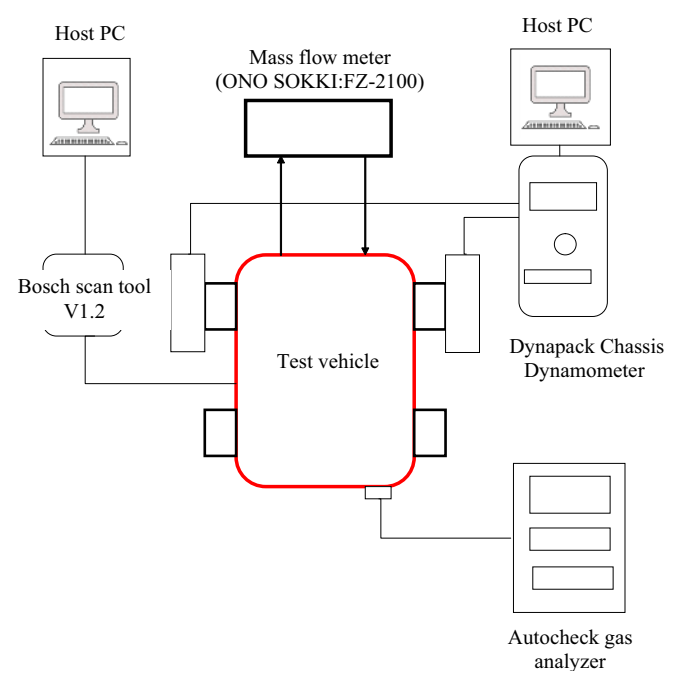

Fig.1. Schematic diagram of theexperimental setup.

Fig. 3 shows the effects of emissions on SI engine fuelled by LPG and gasoline at HOT valve position to WOT valve position. The figure illustrated the emission of $\mathrm{CO}, \mathrm{CO}_{2}, \mathrm{HC}$, $\mathrm{O}_{2}$, and the $\mathrm{NO}_{\mathrm{x}}$. From Fig 3, the CO emission of LPG at the both throttle valve position showed a similar pattern. At HOT valve position, the $\mathrm{CO}$ emission produced near similar value with WOT valve position, in the range of $1500 \mathrm{rpm}$ up to $3500 \mathrm{rpm}$. However, at higher engine speed, 4000rpm, CO emission of gasoline yielded higher value compared to LPG. Since the carbon-hydrocarbon ratio of LPG is low and the LPG burn effectively with more homogeneous mixture[12].The trend showed $\mathrm{CO}_{2}$ emissions of gasoline produced higher value as compared to the LPG for the all engine speed tested. This was attributed to the fact that carbon-hydrogen ratio gasoline is largest value than the LPG [12].In addition, gasoline has complete combustion compared with the LPG for these experiments. The HC emission of LPG was found higher than gasoline for both HOT valve position and WOT 
valve position. This is due to gasoline burned completely comparedwith LPG. The HC emission produced at WOT valve position almost constant for both LPG and gasoline. The LPG was produced high HC compared with gasoline, this may be due to high temperature combustion and non- homogeneity of mixture [12].

The NOx emission of LPG at HOT valve position shows a different pattern as compared to the gasoline fuel and the maximum NOx produced was at 2500rpm as per shown in Fig. 3. At WOT valve position, the NOx production of LPG was higher than gasoline fuel but at 4000rpm the value is nearly zero.It showed that the LPG in liquid phase has higher peak temperature combustion that contributed the increased in NOx emission $[1,3$, 13].Throughout the experiments at WOT valve position, the AFR was maintained at lean condition until 3500rpm. Meanwhile at 4000rpm the AFR changed to rich condition for both of fuel. This is due to the ECU setting of vehicle used and SI engine technology itself. At WOT valve position, the AFR was remained at rich condition and the AFR value became richer as the engine speed increased.
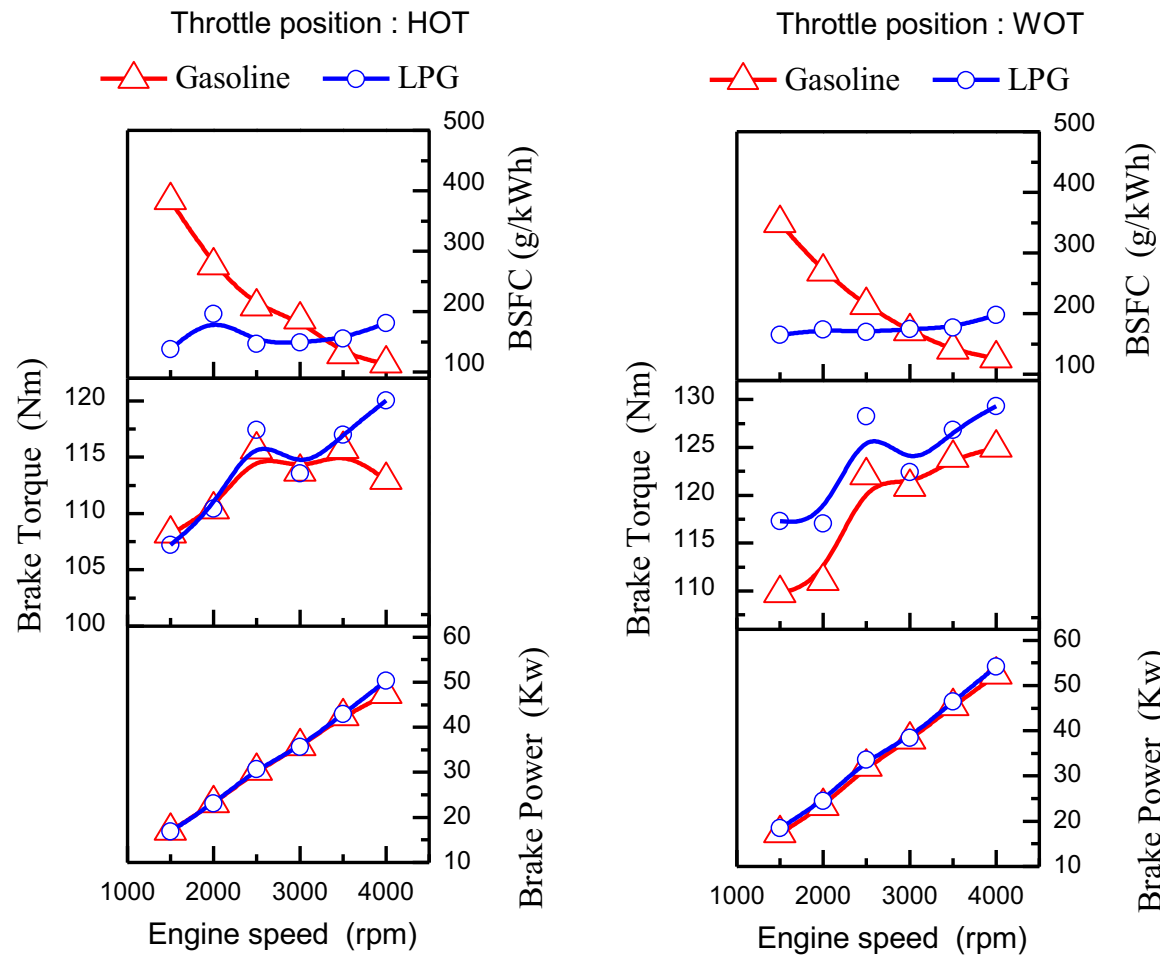

Fig. 2. Performance of LPG and gasoline at different throttle position. 

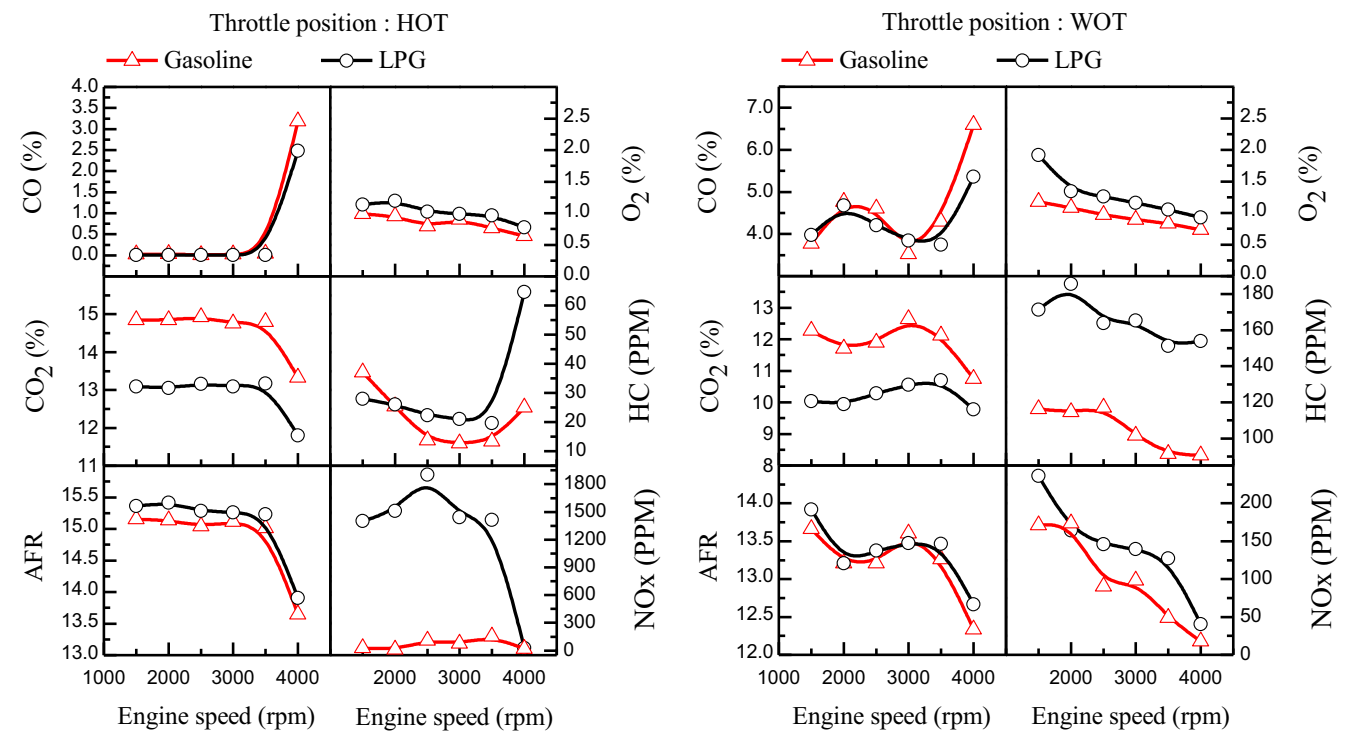

Fig. 3. Emissions of LPG and gasoline at different throttle valve position.

\section{Conclusions}

In a nutshell, performance of the liquid LPG injection was better than gasoline fuel.The BSFC for liquid LPG injection was significantly lower than gasoline fuel. The emission of $\mathrm{CO}$ was also lower as compared to the gasoline fuel. This result shows that LPG is capable to reduce the pollution of the environment. NOx emission produced by LPG is relatively higher than gasoline for both throttle valve position of which may due to the high temperature combustion in the engine cylinders. To reduce the NOx emission of liquid LPG injection, adjustment of the injection duration may be required in order to gives optimum amount of LPG injected in cylinder during combustion.

The author would like to thank the Ministry of Education for partly supporting this research under the Contract Grant, VOT: U427, Short Term Grant (STG) VOT U383 and Centre for Graduate Study, Universiti Tun Hussein Onn Malaysia.

\section{References}

1. H.C. Watson, P.X. Phuong, SAE Technical Paper, (2007)

2. K. Yeom, J. Jang, C. Bae, Fuel, 86, 494 (2007)

3. K. Kang, D. Lee, S. Oh, C. Kim, SAE Technical Paper, (2001)

4. P. Baker, H. Watson, SAE Technical Paper, (2005)

5. M. Campbell, L.P. Wyszynski, R. Stone, SAE Technical Paper, (2004)

6. A. Boretti, SAE Technical Paper, (2011)

7. M. Ihsan Karamangil, Energy policy, 35, 640 (2007)

8. M. Masi, Energy, 41, 252 (2012)

9. A. Boretti, H.C. Watson, SAE Technical Paper, (2009)

10. M.A. Khan, H. Watson, P. Baker, G. Liew, D. Johnston, SAE Technical Pape, (2006) 
11. H.S. Tira, J.M. Herreros, A. Tsolakis, M.L. Wyszynski, Energy, 47, 620 (2012)

12. M. Gumus, Fuel Process. Technol., 92, 1862 (2011)

13. J.A. Caton, M. Mcdermott, R. Chona, SAE Technical Paper, (1997) 